\title{
Tribological Characterization of Some Elastomers Used at Progressive Cavity and Piston Pumps
}

\author{
Mohamed Iyad Al Naboulsi ${ }^{1}$, Niculae Napoleon Antonescu, ${ }^{1, *}$, Alin Dinita ${ }^{1}$, and Marius \\ Morosanu ${ }^{1}$ \\ ${ }^{1}$ University Petroleum-Gas of Ploiesti, Department of Mechanical Engineering, Blvd. Bucuresti, \\ no.39, 100680, Ploiesti, Romania
}

\begin{abstract}
The progressive cavity pump (PCP) is a positive displacement pump, consisting of a polished helical-shaped rod (rotor) turning inside a helical elastomer (stator). PCP has many advantages, but the pump durability is manly limited by elastomer behavior. At piston pumps (PP) used for drilling mud piston has an elastomer sleeve that also limit the durability. Standards like ISO 15136.1 \& 2 for pumps developed by manufactures and users' committees provides requirements for design, quality design verification etc., but do not define specifically the elastomer for the stator or the metal used for the rotor. Each PCP and PP manufacturer used specific materials at pump construction. The aim of this study was to evaluate the tribological behavior of some elastomers such polybutadiene rubber (BR), polybutadiene acrylonitrile rubber (NBR), polybutadiene acrylonitrile carboxylate (XNBR) and polyamide (PA 6) in couples with hard chromium coated steel, nitride steel and cast iron. Were determined friction coefficients and wear on 2 types of friction couples (plane to plane and shoe to plane) on two tribometers and some mechanical proprieties (Young's modulus, ultimate tensile strength, elongation, hardness).
\end{abstract}

\section{Introduction}

In petroleum industry piston pumps (PP) and progressive cavity pumps (PCP) are largely used. The pumped fluid contains formation water, solid particles, dissolved gases such as $\mathrm{O}_{2}, \mathrm{CO}_{2}, \mathrm{H}_{2} \mathrm{~S}$, salts and chlorides all increasing fluid aggressivity, [1,2,3,4]. In acidization operation with PP are inserted in well acids to stimulate the formation deposits and to increase the well production. Drilling mud contains a large amount of solid particles. As presented working pumps fluids are aggressive, and in pumps active elements are subjected to wear. To diminish abrasive wear one of active pump element are made of non-metallic materials such as elastomers. PCP is a positive displacement pump, consisting of a polished helical-shaped rod (rotor) turning inside a helical elastomer (stator). PCP has many advantages, but the pump durability is mainly limited by elastomer behavior. At PP used

\footnotetext{
${ }^{*}$ Corresponding author: nnantonescu@upg-ploiesti.ro
} 
for drilling mud piston has an elastomer sleeve that also limit the durability. Standards like ISO $15136.1 \& 2$ for pumps developed by manufactures and users' committees provides requirements for design, quality design verification etc., but do not define specifically the elastomer for the stator or the metal used for the rotor. Each PCP and PP manufacturer used specific materials at pump construction, [4].

The aim of this study was to evaluate the tribological behavior of some elastomers such polybutadiene rubber (BR), polybutadiene acrylonitrile rubber (NBR), polybutadiene acrylonitrile carboxylate (XNBR) and polyamide (PA 6) in couples with hard chromium coated steel, nitride steel and cast iron. Were determined friction coefficients and wear on 2 types of friction couples (plane to plane and shoe to plane) on two tribometers and some mechanical proprieties.

\section{Experiments}

\subsection{Tested materials characterisation}

To perform wear tests were selected 3 metallic materials widely used at PP cylinder. Chemical composition of materials was established by spectral optical emission with Foundry Master Pro device. In Table 1 it is shown the results obtained.

Table 1. Chemical composition of tested metallic samples.

\begin{tabular}{|c|c|c|c|c|c|c|c|c|c|}
\hline \multicolumn{10}{|c|}{ Chemical elements of sample $1,[\%$ masic $]$} \\
\hline$C$ & $\mathrm{Si}$ & $M n$ & $P$ & $S$ & $\mathrm{Cr}$ & Mo & $\mathrm{Ni}$ & $A l$ & $\mathrm{Cu}$ \\
\hline 0.315 & 0.1845 & 0.7698 & 0.0355 & 0.0025 & 1.008 & 0.1547 & 0.1489 & 0.0479 & 0.229 \\
\hline \multicolumn{10}{|c|}{ Chemical elements of sample $2, \%$ masic } \\
\hline$C$ & Si & $M n$ & $P$ & $S$ & $\mathrm{Cr}$ & Mo & $\mathrm{Ni}$ & $A l$ & $\mathrm{Cu}$ \\
\hline 0.268 & 0.2498 & 0.7459 & 0.0219 & 0.0104 & 0.948 & 0.2049 & 0.7198 & 0.0348 & 0.289 \\
\hline \multicolumn{10}{|c|}{ Chemical elements of sample $3, \%$ masic } \\
\hline$C$ & \multicolumn{2}{|c|}{ Si } & $M n$ & \multicolumn{2}{|c|}{$P$} & $S$ & \multicolumn{2}{|c|}{$\mathrm{Cr}$} & $\mathrm{Cu}$ \\
\hline 3.289 & \multicolumn{2}{|c|}{2.6589} & 0.6214 & \multicolumn{2}{|c|}{0.0948} & 0.1048 & \multicolumn{2}{|c|}{0.1089} & .2189 \\
\hline
\end{tabular}

To analyse the metallographic structure of the 3 metallic samples, specimens were prepared, and the surfaces were attacked with $5 \%$ Nital solution. The images obtained with Olympus BX 60M are in Figure 1.

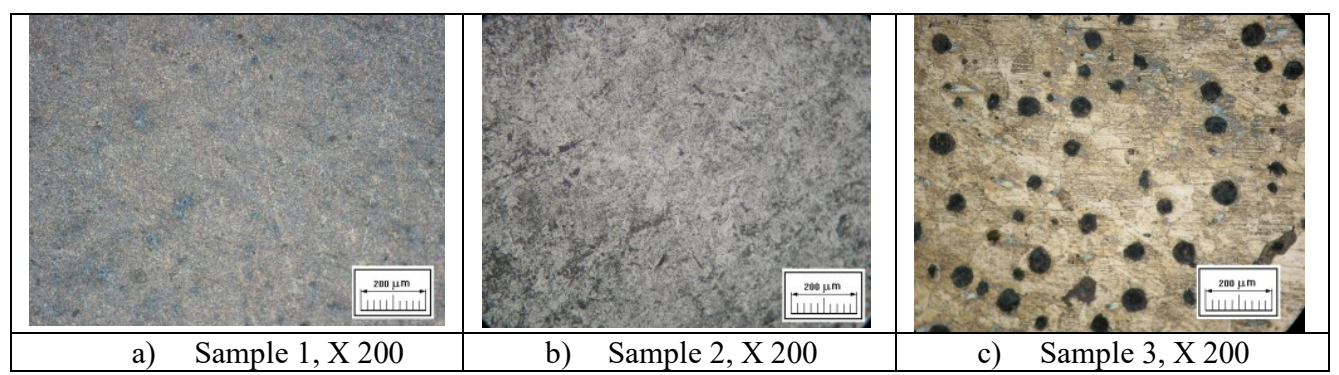

Fig.1. Metallographic structure of the metallic samples. 
From Figure 1 the samples 1 and 2 are hypoeutectoid steels and has a martensite and chromium and nickel carbide and sample 3 it is a cast nodular iron in a ferrite-pearlite matrix. The chemical composition presented in Table 1 show that sample 1 it is $34 \mathrm{CrMo} 4$, EN 10083-3:2006, sample 2 it is 25CrMo4, EN 10083-3:2006, and sample 3 it is EN-GJSHB 230, EN 1563:2018. Sample 1 was gas nitride obtaining a hardness of $540 \mathrm{HV}$, the sample 2 was hard chromium plated obtaining a hardness of 910 HV1. In Figure 2, the thickness of hard chromium plated stratum $(0.1 \mathrm{~mm})$ are presented.

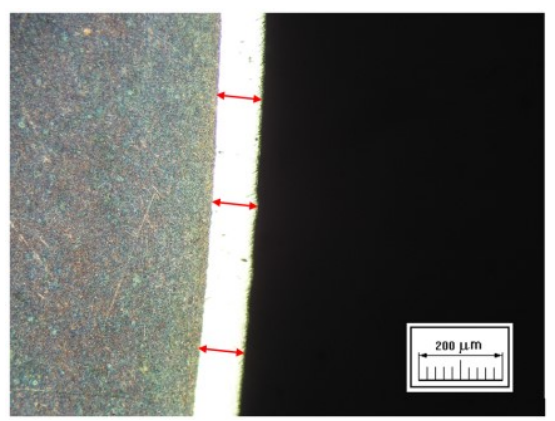

Fig.2. Hard chromium plated stratum thickness.

Elastomers type and main proprieties are presented in Table 2. Were tested polybutadiene rubber (BR), polybutadiene acrylonitrile rubber (NBR), polybutadiene acrylonitrile carboxylate (XNBR) and polyamide (PA 6) with commercial name Ertalon 6 SA.

Table 2. Mechanical characteristics of tested elastomers.

\begin{tabular}{|c|c|c|c|c|}
\hline \multirow{2}{*}{$\begin{array}{c}\text { Mechanical } \\
\text { characteristic }\end{array}$} & \multicolumn{4}{|c|}{ Elastomer type } \\
\cline { 2 - 5 } & NBR & XNBR & BR & PA 6 \\
\hline $\begin{array}{c}\text { Young's modules, } \\
\text { [MPa] }\end{array}$ & 3.5 & 4.5 & 4.5 & 3.25 \\
\hline $\begin{array}{c}\text { Ultimate strength, } \\
\text { min. [MPa] }\end{array}$ & 20 & 15 & 15 & 76 \\
\hline $\begin{array}{c}\text { Elongation at } \\
\text { break, min. [\%] }\end{array}$ & 350 & 300 & 300 & 50 \\
\hline Hardness, [Shore] & $80 \pm 3$ & $80 \pm 3$ & $70 \pm 5$ & 73 \\
\hline
\end{tabular}

There are many pumps manufacturers interested in recommendations for elastomers used in pumps construction. In the present there is no standard to limit the use of elastomers. The ISO sub-committee tasked with reviewing ISO 15136-1 including specialist and pumps manufacturer representatives such as PCM, Weatherford, Netzsch, operators as Exxon, Total, Shell etc. do not impose some specific elastomers, [4]. Thus, the pump manufacturers must perform tests in order to choose the best elastomer material for specific application.

\subsection{Wear tests}

\subsubsection{Wear tests on CSM pin -on-disk microtribometer}

Disk samples with Ø $30 \mathrm{~mm}$ and thickness of $10 \mathrm{~mm}$ were prepared of polybutadiene rubber (BR), polybutadiene acrylonitrile rubber (NBR), polybutadiene acrylonitrile carboxylate (XNBR) and polyamide (PA 6). 
Static partner was with cubic shape with dimensions of $3.97 X 3.97 X 3.97 \mathrm{~mm}$ of 34CrMo4, 34CrMo4 nitrided and EN-GJS-HB 230. Due to the small dimensions of cubic samples, the hard chromium plated could not be obtained.

Tests were conducted in dry conditions in air $\mathrm{RH}=57 \%$, at temperature of $20^{\circ} \mathrm{C}$, normal load of $2 \mathrm{~N}(0.12689 \mathrm{~Pa})$, sliding speed of $0.2 \mathrm{~m} / \mathrm{s}$ at a radius of $10 \mathrm{~mm}$, friction length of 50 $\mathrm{m}$, [5]. In Figure 3 it is shown the image of Instrument $\mathrm{X}$ tribometer screen caption for couple EN-GJS-HB 230 with elastomer BR.

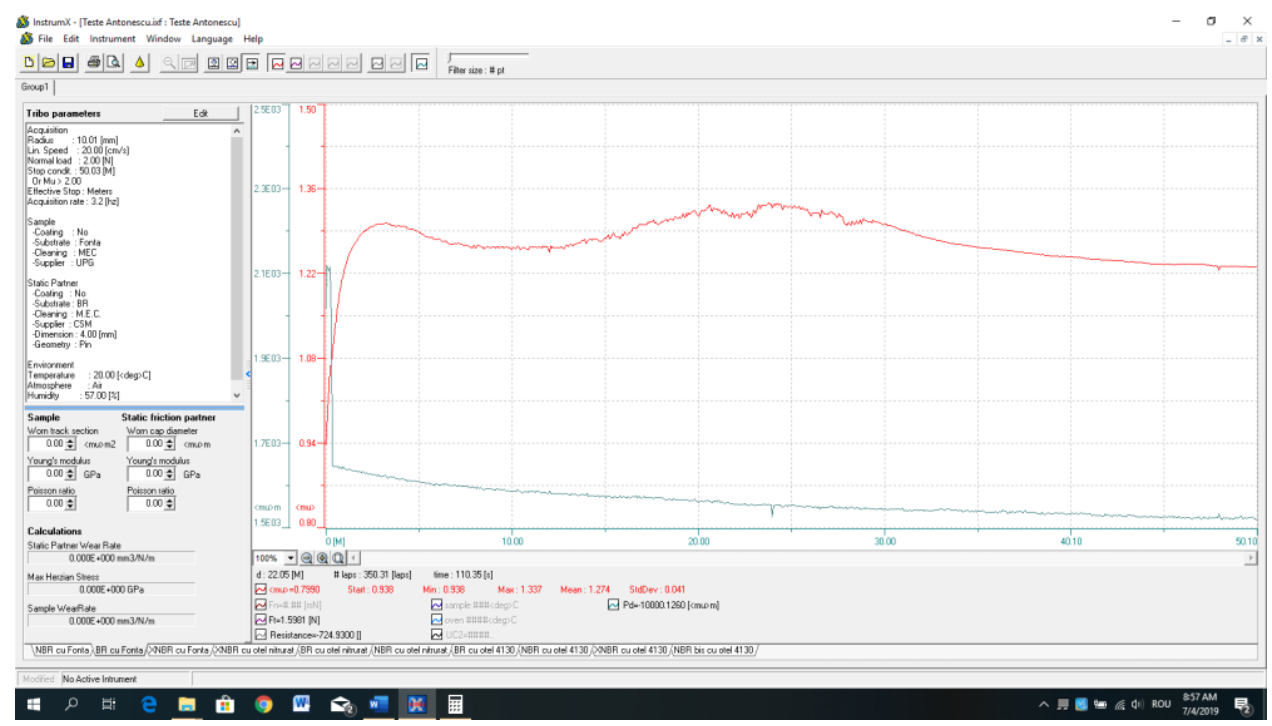

Fig.3. Image of Instrument X tribometer screen caption for couple EN-GJS with elastomer BR.

In Figure 4 we present the friction coefficient variation for steel $34 \mathrm{CrMo} 4$ with different elastomers.

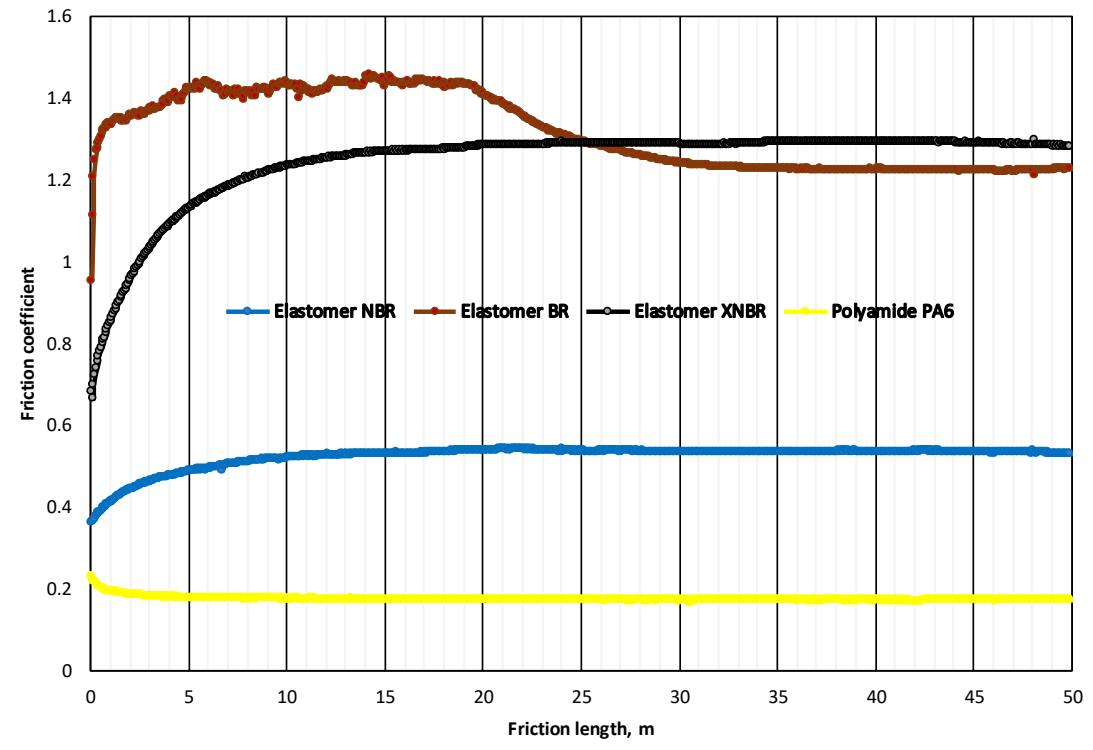

Fig.4. Friction coefficient vs. friction length for couples 34CrMo4- elastomers. 
We could observe from fig.4 that the smallest values of friction coefficients were obtained for polyamide PA6 in couple with steel 34CrMo4. Similar results were obtained for $34 \mathrm{CrMo} 4$ nitrided and EN-GJS-HB 230. In Table 3 are presented the results obtained for tested materials couples.

Table 3. Friction coefficients values for tested materials couples.

\begin{tabular}{|c|c|c|c|c|}
\hline Materials couples & $\begin{array}{c}\text { Hertzian } \\
\text { pressure }\end{array}$ & $\begin{array}{c}\text { Maximum } \\
\text { value of } \\
\text { friction } \\
\text { coefficient } \\
{[-]}\end{array}$ & $\begin{array}{c}\text { Average } \\
\text { value of } \\
\text { friction } \\
\text { coefficient } \\
{[-]}\end{array}$ & $\begin{array}{c}\text { Friction } \\
\text { coefficient } \\
\text { stabilized } \\
\text { at } 50 \mathrm{~m} \\
{[-]}\end{array}$ \\
\hline Rubber NBR with EN-GJS-HB 230 & \multirow{12}{*}{0.12689} & 0.812 & 0.796 & 0.812 \\
\hline Rubber BR with EN-GJS-HB 230 & & 1.337 & 1.274 & 1.2313 \\
\hline Rubber XNBR with EN-GJS-HB 230 & & 1.006 & 0.975 & 0.9768 \\
\hline Rubber NBR with 34CrMo4 nitrided & & 0.978 & 0.850 & 0.828 \\
\hline Rubber BR with 34CrMo4 nitrided & & 1.269 & 1.141 & 1.086 \\
\hline Rubber XNBR with 34CrMo4 nitrided & & 0.878 & 0.849 & 0.878 \\
\hline Rubber NBR with 34CrMo4 & & 0.541 & 0.521 & 0.530 \\
\hline Rubber BR with 34CrMo4 & & 1.455 & 1.315 & 1.225 \\
\hline Rubber XNBR with 34CrMo4 & & 1.296 & 1.242 & 1.281 \\
\hline Polyamide PA6 with 34CrMo4 nitrided & & 0.258 & 0.151 & 0.143 \\
\hline Polyamide PA6 with EN-GJS-HB 230 & & 0.250 & 0.182 & 0.175 \\
\hline Polyamide PA6 with 34CrMo4 & & 0.231 & 0.173 & 0.171 \\
\hline
\end{tabular}

The metallic materials type does not have an important influence on friction coefficients as we could see from table 3 .

\subsubsection{Wear tests on Amsler A135 type tribometer}

On Amsler tribometer were used cylinder- shoe couples. Cylinder samples with $\varnothing 30 \mathrm{~mm}$ were made of 25CrMo4 hard chromium plated, 34CrMo4 nitrided and EN-GJS-HB 230. Shoe samples were made of polybutadiene rubber (BR), polybutadiene acrylonitrile rubber (NBR), polybutadiene acrylonitrile carboxylate (XNBR) and polyamide (PA 6). Tests were conducted in dry conditions (air $\mathrm{RH}=57 \%$ at $20^{\circ} \mathrm{C}$ ambient temperature), at a sliding speed of $0.314 \mathrm{~m} / \mathrm{s}$ and a normal load of $500 \mathrm{~N}$ for 30 minutes. Were established friction coefficients and gravimetric wear.

In Figure 5 we present the friction coefficients for couple cylinder of EN-GJS-HB 230shoe of rubber BR, NBR, XNBR and polyamide PA6.

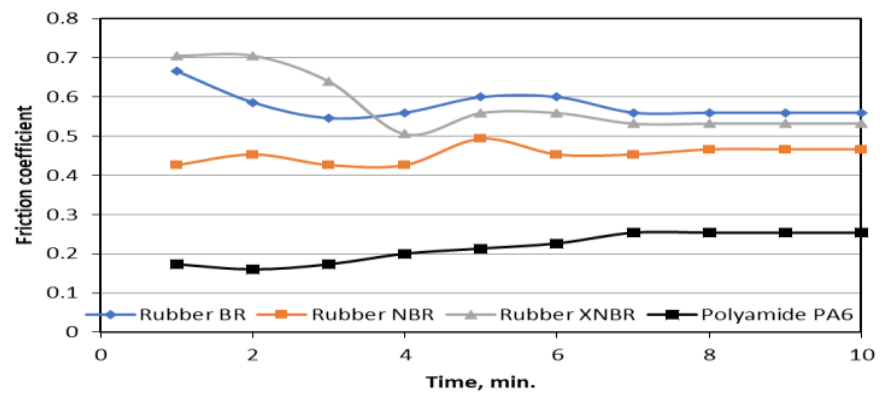

Fig.5. Friction coefficients for couples' cylinder of EN-GJS-HB 230- shoe of rubber BR, NBR, XNBR and polyamide PA6. 
Similar results were obtained for all tested couples. In figure 6 are the wear curves for tested elastomers. Gravimetric wear was obtained with a analytical balance type Mettler H35 with $10^{-4}$ grams precision.

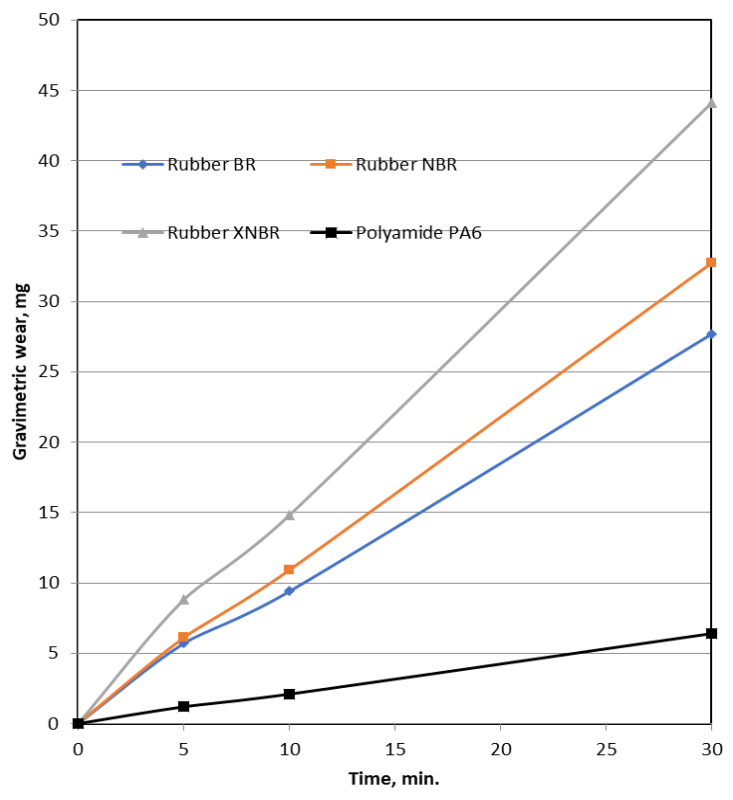

Fig.6. Wear curves for tested elastomers.

Due to the high hardness difference between metallic materials and elastomers were not observed wear at tested metallic materials.

\section{CONCLUSIONS}

Were analysed 3 largely used metallic materials at pumps construction. Wear tests performed on plane-to-plane couples on CSM tribometer and on cylinder-shoe on Amsler show similar values of friction coefficients for the same materials couples. Differences are caused by temperature influence and the rigidity of elastomer materials. The best wear behaviour was obtained for polyamide PA6. Metallic material has no significative influence on friction coefficients and wear at tested materials couples. This study will be continued with wear tests in the presence of working medium with solid particles and corrosive behaviour.

\section{References}

1. H. Wang, S. Wang, and X. Lv, Mechanika, 22, 4, 308(2016)

2. R.G. Ripeanu, V. Ispas, D. Ispas, FME Transactions, 43, 3, 192 (2015)

3. B. Guo, X. Liu, X. Tan, Petroleum Production Engineering (GPP, Elsevier 2017)

4. K.L. Kishiuchi, Recommended Practice Elastomer Classification and Characterization (C-FER Technologies 2004)

5. I. Tudor, A. Popescu, R.G. Ripeanu, A.C. Drumeanu, V. Braic, M. Balaceanu, A. Vladescu, M. Braic, J. Balk. Trib. Assoc., 15, 2, 156 (2009) 